\title{
XI International Conference "Systems for Design, Technological Preparation, Production, and Control over the Life Cycle of an Industrial Product" (CAD/CAM/PDM-2011)
}

DOI: $10.1134 / \mathrm{S} 0005117911080133$

\section{TOPICS OF THE CONFERENCE:}

- Organizing the structures of technical and software means of design and control. Means of interaction, data structures, international standards.

- Computer graphics and CAD/CAM/PDM systems in education (education programs for the corresponding disciplines, methodical materials, testing). Virtual reality in industrial systems.

- Integrated industrial systems and control for technological processes. PDM systems.

- Design in engineering and construction.

- Design in radioelectronics.

\section{ORGANIZERS:}

- Russian Fund for Basic Research (RFBR)

- Russian Academy of Sciences (RAS)

- Ministry of Education and Science of Russian Federation

- Trapeznikov Institute of Control Sciences of the RAS

- Khrunichev State Space Scientific-Industrial Center (FGUP GKNPTs)

- Moscow Technical University of Communication and Computer Science (MTUSI)

- Rocket Space Center "Energy" (RKTs)

- Moscow State Technical University "Stankin"

- International Academy of Informatization

\section{KEY DATES:}

Up to September 15, 2011 - conference and/or demo session participation application, registration fee transfer, abstracts of the talks (at most one A5 page).

Up to October 1, 2011-full versions of the talks.

We accept applications, abstracts, and talks at the following address: conf18@spm.ipu.ru

CURRENT INFORMATION (application forms, proceedings templates, etc.) is on http://lab18.ipu.rssi.ru

CONFERENCE LANGUAGES: Russian, English

ORGANIZING COMMITTEE CONTACTS: 117997, Russia, Moscow, ul. Profsoyuznaya 65, ICS RAS, Organizing Committee of the CAD/CAM/PDM-2011 Conference.

Phone (495) 334-93-50; fax (495) 334-91-29.

Chair: Artamonov Evgenii Ivanovich, Sc.D., Prof.

Secretary: Smirnov Sergei Vladimirovich, Ph.D. 